\title{
Erratum to: Differential distribution of dystrophin and $\beta$-spectrin at the sarcolemma of fast twitch skeletal muscle fibers
}

Mcrae W. Williams • Robert J. Bloch

Published online: 2 July 2010

(C) Springer Science+Business Media B.V. 2010

Erratum to: J Muscle Res Cell Motil

DOI 10.1023/A:1005512217552

In Fig. 5 of the original publication, the authors mistakenly included images taken from quadriceps muscle that had been used in a previous publication, rather than original images of the tibialis anterior. The corrected figure is shown below. The authors apologize for this error.

The online version of the original article can be found under doi:10.1023/A:1005512217552.

M. W. Williams · R. J. Bloch $(\bowtie)$

Department of Physiology, School of Medicine, University of Maryland, 660 W. Redwood St., Baltimore, MD 21201, USA

e-mail: rbloch@umaryland.edu 

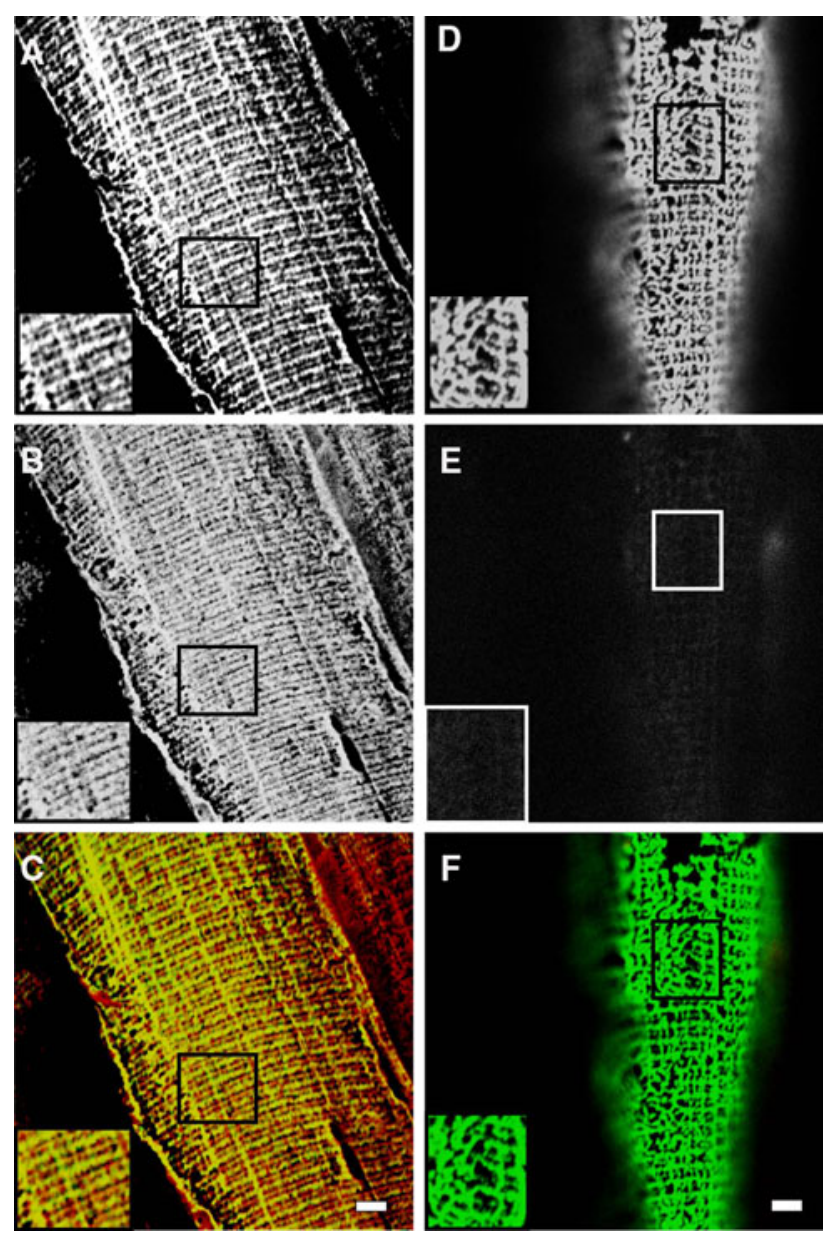

Fig. 5 Immunolabeling of wild type and $m d x$ muscle. Wild type and $m d x$ mice were sacrificed by perfusion fixation with $2 \%$ paraformaldehyde. Tibialis anterior muscles from wild type $(\mathbf{a}-\mathbf{c})$ and $m d x(\mathbf{d}-\mathbf{f})$ mice were fixed further and snap frozen. Cryosections were double immunolabeled for $\beta$-spectrin with 9050 (a, d), and for dystrophin with Dys2 (b, e). Computer-generated composite images $(\mathbf{c}, \mathbf{f})$ show $\beta$-spectrin in green, dystrophin in red, and regions containing both proteins in yellow. Settings were adjusted to make the pixel intensities for both proteins in costameres of wild type muscle approximately equal. The same settings were then used to obtain the images for the $m d x$ sample. Dystrophin in intercostameric regions as well as at costameres was evident in the wild type (e.g., regions shown in red in $\mathrm{C}$ and $\mathrm{C}$, inset) but not in the $m d x$. Bars, $5 \mu \mathrm{m}$ 